Running head: SOCIAL MEMORY

\title{
Reduced autobiographical memory specificity affects general distress through poor social support
}

Tom J. Barry ${ }^{1,2}$, Meghan Vinograd ${ }^{3}$, Yannick Boddez ${ }^{4,5}$, Filip Raes ${ }^{5}$, Richard E. Zinbarg6, ${ }^{6,7}$ Sue Mineka ${ }^{6,7}$, Michelle G. Craske ${ }^{3 *}$

${ }^{1}$ Experimental Psychopathology Lab, Department of Psychology, The University of Hong Kong, Hong Kong.

${ }^{2}$ Researching Emotional Disorders and Development Lab, The Institute of Psychiatry, Psychology \& Neuroscience, King’s College London, London, United Kingdom.

${ }^{3}$ UCLA Anxiety and Depression Research Centre, Department of Psychology, University of California Los Angeles, California, United States.

${ }^{4}$ Department of Clinical Psychology and Experimental Psychopathology, University of Groningen, Groningen, The Netherlands

${ }^{5}$ Centre for Learning Psychology and Experimental Psychopathology, University of Leuven, Leuven, Belgium.

${ }^{6}$ Department of Psychology, Northwestern University, Evanston, Illinois, United States.

${ }^{7}$ The Family Institute at Northwestern University, Evanston, Illinois, United States

Abstract word count: 173

Word count (Abstract, main text and references): 5940

Figures: 1

Tables: 2 


\begin{abstract}
Sharing specific autobiographical events is likely to influence the support people give us; a person who shares little detail of their lives may be unlikely to attract social support and this may in turn contribute towards anxious and depressive symptoms. Participants $(\mathrm{N}=142)$ reported memories evoked by negative and positive cue words and these memories were coded for whether or not they referred to a specific event lasting less than 24 hours. At this time (T1) and one year later (T2), participants also completed the UCLA Life Stress Interview (LSI), which includes a measure of social support, and measures of depression and anxiety comprising a general distress latent construct. The tendency to recall fewer specific memories was associated with lower social support given by friends and romantic partners and this was in turn associated with elevated general distress at T2, even when accounting for T1 social support and general distress. Our findings contribute to the literature regarding the social function of memory and suggest another route via which reduced specificity contributes to emotional disorders.
\end{abstract}

Keywords: Memory; Specificity; Overgeneral; Depression; Adolescence. 
The tendency to recall autobiographical memories from one's past with little specificity has been associated with the presence and course of a range of emotional disorders (Griffith, Kleim, Sumner, \& Ehlers, 2012; Kleim \& Ehlers, 2008; Ono, Devilly, \& Shum, 2015; Van Vreeswijk \& De Wilde, 2004). Despite several decades of work in this area, questions remain regarding the mechanisms by which autobiographical memory specificity influences the symptoms of these disorders. Proposed mechanisms focus on how people cope with negative life events and their experience of negative emotions (Williams et al., 2007). This neglects the social context in which autobiographical memories are shared, or how sharing limited details of one's autobiographical past might influence our relationships with others. Although there is evidence that sharing memories with other people can influence the warmth and closeness they feel towards us (Alea \& Bluck, 2007) and that the emotional support that we receive from other people can influence mental health (Dour et al., 2014) no study has yet examined whether individual differences in autobiographical memory specificity can influence social support, and whether this in turn predicts differences in the severity of emotional disorder symptoms.

Individual differences in autobiographical memory specificity are typically assessed using the Autobiographical Memory Test (AMT; Williams \& Broadbent, 1986) in which participants are given cue words to prompt recall of a memory (Williams \& Broadbent, 1986). Autobiographical memory specificity is then operationalised as the number or proportion of memories recalled within the AMT that are specific - those which involve a single event lasting 24 hours or less. If given the cue word skill, a person with reduced autobiographical memory specificity (rAMS) might offer the non-specific memory of "I'm no good at do-it-yourself projects" whereas a person with greater AMS might say "Several weeks ago I spent the day building my child a toy kitchen and was unable to finish it properly."

Research to-date has explored the mechanisms which are thought to reduce memory 
specificity, as well as the consequences of reduced specificity that mediate its association with emotional disorders. This work was synthesized by Williams (2006) and Williams et al. (2007) in their seminal Capture and Rumination, Functional Avoidance and eXecutive capacity (CaRFAX) model of rAMS. These three CaRFAX pathways work both independently and in combination to compromise memory specificity (Sumner et al., 2014), though the exact nature of their interaction may differ between age-groups (Stewart, Hunter $\&$ Rhodes, 2017). Comprised memory specificity then leads to several consequences that are hypothesised to in turn contribute to the emergence and maintenance of emotional disorders.

The first of these consequences suggests that reduced specificity leads to difficulty using the details of previous events to inform the selection of solutions for problems. As such, both adolescents and adults with rAMS give less direct and effective solutions to hypothetical problems than people with higher specificity (Arie, Apter, Orbach, Yefet, \& Zalzman, 2008; Goddard, Dritschel, \& Burton, 1996, 1997; Raes et al., 2005; Sutherland \& Bryant, 2008). Reduced specificity might also compromise one's ability to imagine specific details of, and plan for, one's personal future, which might explain the observed association between reduced memory specificity and hopelessness (Arie et al., 2008; Evans, Williams, O'loughlin, \& Howells, 1992). Problem solving difficulties and heightened feelings of hopelessness are also thought to explain avoidant coping amongst adolescents and adults with rAMS (Harris et al., 2015). If a person feels unable to confront and solve problems directly, they might avoid problems altogether. Avoidant coping also reduces exposure to negative emotions which in turn is thought to restrict one's ability to learn how to regulate and cope with these emotions when they inevitably occur (Hermans, Raes, \& Eelen, 2005). People with rAMS may also be less likely to benefit from positive experiences as they may have difficulty recalling specific information about these experiences and how they can be replicated (Raes, Williams, \& Hermans, 2008).

Each of these mediational mechanisms refers to the difficulty that individuals with 
rAMS have in regulating their own emotions and in planning for and dealing with events in their life. These mechanisms neglect the social consequences of memory recall and the way in which sharing memories may have consequences for communication with others (Vanderveren, Bijttebier, \& Hermans, 2017). However, research has yet to consider how rAMS might influence our relationships with other people and in particular the support that they offer us. For example, offering only general memories of the past, such as not being good at do-it-yourself projects, may attract less support from others than if we share specific instances in which help was needed, such as in building a toy kitchen for one's child.

Theories of autobiographical memory posit that the recall of past events serves a social function. The recall and sharing of our autobiographical past allow us to learn more about people and develop intimacy with them based on common experiences (Alea \& Bluck, 2003). Sharing of specific or personally relevant memories with romantic partners has therefore been associated with warmth and closeness of relationships (Alea \& Bluck, 2007). Also, Beike, Brandon and Cole (2016) found that, amongst unacquainted pairs of adults, the extent to which specific memories were shared was associated with closeness amongst these pairs.

People who share more specific memories with one another may feel closer, and as a result, they might be more likely to offer social support. Although social support can be operationalized in several different ways, perceived social support represents the most common index (Ibarra-Rovillard \& Kuiper, 2011). This refers to the extent to which we perceive others as supporting us emotionally and practically, and the extent to which they are available to advise and socialize with us (Dour et al., 2014). Individual differences in perceived social support from peers and parents has been found to predict changes in depressive symptoms among both adolescents and adults (Dour et al., 2014; Leskelä et al., 2006; Stice, Ragan, \& Randall, 2004).

As such, there is evidence that both rAMS and poor social support from other people 
are associated with a range of emotional disorders (Williams et al., 2007; Dour et al., 2014) and that the extent to which we share autobiographical memories can influence our relations with other people (Beike et al., 2016). However, to our knowledge, there has not yet been any investigation of the association between rAMS and perceived social support, or whether reduced autobiographical memory specificity indirectly affects the symptoms of emotional disorders through poor social support. It is conceivable that people who are better able to retrieve specific memories from their past, and so are also better able to share these memories with other people, are likely to receive greater warmth and closeness from others as a result of sharing these memories with them (Beike et al., 2016). As such, when confronted with daily stressors, they may also receive more support from these other people given the closeness that is felt between them. This support may in turn enable them to better manage or cope with these stressors and so protect them against a worsening of emotional disorder symptoms. Conversely, people who are less able to retrieve such memories might receive less support from other people and so may be more vulnerable to a subsequent worsening of symptoms.

The investigation presented herein provides the examination of these longitudinal pathways. Problems with autobiographical memory specificity measured at Time 1 were hypothesized to be associated through lower social support over the next year, which was in turn hypothesized to be associated with a worsening of emotional disorder symptoms by Time 2 at the end of the year. Given the cross-sectional associations that are expected between our study variables, our longitudinal analysis also takes into account individual differences in symptoms and social support measured at Time 1. We operationalise the symptoms of emotional disorders in terms of general distress. This broad factor captures the aspects of negative affect shared by depression and anxiety and so accounts for the comorbidity that exists between these problems (Naragon-Gainey, Prenoveau, Brown, \& Zinbarg, 2016; Prenoveau et al., 2010). More specifically, this factor is measured by taking 
participants' responses on a range of questionnaires that assess the severity of a range of depressive and anxious symptoms, and also the symptoms of specific fear- or anxiety- related disorders, and then creates a latent construct wherein the common variance between these measures is captured. Given the evidence that rAMS is associated with a range of disorders and not just Depression (Williams et al., 2007), this operationalisation of emotional disorder symptoms was used in order to enable us to examine the effects of rAMS within a transdiagnostic context.

\section{Method}

\section{Participants and procedure}

Participants were recruited as part of the prospective University of California, Los Angeles (UCLA) and Northwestern University (NU) Youth Emotion Project (YEP). High school juniors were recruited from two schools in the greater Los Angeles and Chicago areas. 1269 students were invited to participate, of which 627 provided assent and parental consent and then completed the first assessment battery. Approximately nine months after the baseline assessment, a random subsample completed the Autobiographical Memory Test $(N=333$; T1), and the full sample completed measures of social support and general distress. Participants repeated the measures of social support and general distress at Time 2 (T2) approximately one year later. A total of 142 participants completed all measures used in the current study. A full description of the recruitment process, the characteristics of the whole sample and the other measures given to these participants has been provided elsewhere (Zinbarg et al., 2010).

In line with previous analyses that used the broader YEP sample (Prenoveau et al., 2010) participants included in this analysis had a mean age of 16.1 years at T1 (Range $=15$ $17 ; S D=.4$ ) and $78.2 \%$ of them were female. $52.8 \%$ of participants identified as Caucasian or white, $16.2 \%$ identified as Hispanic or Latin American, 9.2\% identified as African American or Black, 4.2\% identified as Asian, $7.0 \%$ identified as Other and $10.6 \%$ identified 
as having more than one ethnicity. $54.9 \%$ of participants were from the UCLA site and $45.1 \%$ from the Northwestern site. $56.3 \%$ of participants had at least one college-graduate parent. $33.8 \%$ of participants had two parents with full-time employment and $30.2 \%$ had only one parent in full-time employment. Also, in line with previous YEP analyses, $14.9 \%$ of participants in the present study were classified as low scorers in the Revised Eysenck Personality Questionnaire specific to neuroticism (EPQ-R-N; Eysenck \& Eysenck, 1975; Eysenck, Eysenck, \& Barrett, 1985), 30.6\% were medium-scorers and 54.5\% were highscorers.

\section{Measures}

\section{General distress}

In line with the tri-level model (Naragon-Gainey et al., 2016; Prenoveau et al., 2010), the present analyses operationalized general distress using a latent construct that included items from the Inventory to Diagnose Depression (IDD; Zimmerman, Coryell, Corenthal, \& Wilson, 1986), the Mood and Anxiety Symptoms Questionnaire (MASQ; Watson et al., 1995), the Social Phobia Scale (SPS; Mattick \& Clarke, 1998), the Situational Fears

Questionnaire (SFQ) and the Fear Survey Schedule - II (FSS; Geer, 1965). See Prenoveau et al. (2010) for a full description of each questionnaire and the selected items.

\section{Autobiographical Memory Specificity}

Individual differences in autobiographical memory specificity were assessed using the Autobiographical Memory Test (AMT; Williams \& Broadbent, 1986). The full test consisted of six positive cues (safe, ambitious, peace, hope, brave, interested) and six negative cues (disappoint, inferior, hurt, frustrated, tense, regret) presented in alternating order. These utterances were audio-recorded and coded later. Memories were coded as specific (an event lasting less than 24 hours), extended (an event lasting more than 24 hours), categoric (an event that occurred on multiple occasions), semantic associate (a response with general semantic information but no personal memory) or omission (no response). Mean kappas for 
within-site $(N=73)$ and cross-site $(N=37)$ reliability were both .78 . In line with the psychometric evidence regarding the factor structure of the AMT (Griffith et al., 2009, 2012; Heron et al., 2012; Takano, Mori, Nishiguchi, Moriya, \& Raes, 2017), the proportion of specific memories that were recalled relative to the total number of cues was then calculated.

\section{Social Support}

The UCLA Life Stress Interview (LSI; Hammen, Ellicott, Gitlin, \& Jamison, 1989) was used to assess individual differences in social support. Although the LSI is traditionally used to assess interpersonal and non-interpersonal aspects of chronic and episodic stress, the interpersonal domains assessed in the LSI also capture an individual's level of social support. In this semi-structured interview, interpersonal stress related to one's closest friend, other friends or social circle, romantic life and immediate family over the previous year is queried. For romantic relationships, a score is assigned for any romantic relationship that the participant has had during the assessment period whether it is a committed relationship or if they 'dated'. During the LSI, the interviewer asks participants how close they feel within each of the aforementioned relationships, whether they could confide in this person and if they feel they are understood and accepted by them, and whether they are supported in a onesided or mutual way. The interviewer also probes how participants resolve conflict if it occurs or how they anticipate they would resolve it in the event they have not experienced it. Participants are then given a score by the interviewer from one (superior conditions) to five (exceptionally poor conditions) in each of the domains. Here, the scores for each index were reversed such that a high score represents strong social support. Good intra-class coefficients (ICC) were evident when comparing LSI scores within-site at $\mathrm{T} 1(\mathrm{ICC}=.87)$ and T2 $(\mathrm{ICC}=$ $.81)$ and cross-site at $\mathrm{T} 1(\mathrm{ICC}=.84)$ and $\mathrm{T} 2(\mathrm{ICC}=.80)$.

\section{Analysis strategy}

Analyses were conducted using STATA 14.2. First, given the disproportionate number of females in the sample relative to the number of males, we first examined whether 
there were differences between sexes in the proportion of specific memories recalled in the AMT and in each of the indices of social support at each time point. Also, as the LSI measures social support across several different relationships, to reduce the number of models tested and therefore the possibility of false positives within these analyses, we followed a stepped approach. We first used linear regression to examine the extent to which the different LSI indices explained unique variance in the proportion of specific memories recalled in the AMT. Although this regression involves predicting T1 specificity with T2 indices of social support, the intention here is to examine those aspects of social support which show a unique association with specificity so that a composite score could then computed by combining scores on each interpersonal subdomain that showed a unique association with AMT scores. We then used this composite social support index within the path models. Indices for LSI subdomains which did not show a unique association with specificity were dropped from further analyses. We also computed factor scores for the general distress construct for each participant at each time point. These factor scores then operated as the dependent variables in the longitudinal structural equation model (SEM).

Our SEM then tested the associations between memory specificity measured at T1 and social support and general distress measured at T2, a year later, whilst accounting for the variance explained by social support and general distress from T1. Although social support and general distress were both measured at T2, the LSI measures social support over the past 12 months, whereas the measures included in the general distress construct capture symptoms over the past week. As such, we assessed the extent to which individual differences in the proportion of specific memories recalled in the AMT at $\mathrm{T} 1$ predicted variability in social support for the next 12 months (as recalled at T2), and the extent to which this predicted variability in general distress at the time of $\mathrm{T} 2$ whilst accounting for the variance in general distress explained by social support and general distress at T1. An additional model was used to rule out whether specificity had an indirect effect on social support through general 
distress.

\section{Results}

The mean proportion of specific memories recalled by participants in the AMT at T1 was $.80(S D=.17)$. At T1, on average participants reported a moderate amount of support in each of the four domains (Close friend: $M=2.83, S D=.72$; Social circle: $M=2.62, S D=$ .69 ; Romantic: $M=2.58, S D=.69$; Family: $M=2.42, S D=.75)$. Similar means were present in the T2 LSI (Close friend: $M=2.79, S D=.85$; Social circle: $M=2.66, S D=.71$; Romantic: $M=2.64, S D=.60$; Family: $M=2.61, S D=.75)$. There were no differences between males and females in the proportion of specific memories recalled in the AMT, $t(140)=0.54, p=$ .593 , or for any of the social support indices at T1 (smallest $p=.338$ ) or T2 (smallest $p=$ .367). As such, sex was not included in any of the analyses.

When the T2 social support indices were entered together as predictors of specificity scores in a linear regression, support from one's social circle, $B=.056, S E=.025, p=.024$, and one's romantic partner, $B=.054, S E=.020, p=.037$, predicted significant unique variance in specificity (see Table 1). As such, these scores were combined to create an index of overall social support for the longitudinal analysis. This combined score is referred to as social support in the subsequent analyses

\section{Longitudinal Analysis}

Table 2 presents the correlations between study variables and Figure 1 depicts the longitudinal structural equation model. T1 memory specificity predicted a significant amount of variance in the T2 index for support (from one's social circle and romantic partner), $B=$ $1.374, S E=.434, Z=3.17, p=.002,95 \%$ CI $[0.52,2.22]$, even when accounting for the variance in T2 social support explained by T1 social support, $B=.341, S E=.068, Z=4.99, p$ $<.001,95 \%$ CI $[0.21,0.48]$ (pathway a, Figure 1).

There was also a significant effect of T2 support on T2 general distress, $B=-.062, S E$ $=.023, Z=-2.65, p=.008,95 \% \mathrm{CI}[-0.11,-0.02]$ (pathway $\mathrm{b}$, Figure 1). 
$\mathrm{T} 1$ specificity did not explain a significant amount of variance in T2 general distress, $B=-.080, S E=.133, Z=-.60, p=.548,95 \%$ CI $[-0.34,0.18]$ (pathway $\mathrm{c}^{1}$, Figure 1).

In line with our hypotheses, there was a significant indirect effect of $\mathrm{T} 1$ specificity on T2 general distress through T2 support, $B=-.085, S E=.042, Z=-2.03, p=.042,95 \%$ CI [$0.167,-0.003$ ] (pathway $c^{2}$, Figure 1). This effect took into account the effects of T1 general distress, $B=.794, S E=.102, Z=7.76, p<.001,95 \%$ CI [0.59, 0.99], and T1 social support, $B=-.021, S E=.009, Z=-2.34, p=.019,95 \%$ CI $[-0.039,-0.003]($ see Figure 1$)$ on T2 general distress.

The second, alternative, longitudinal model found no evidence that T1 specificity was indirectly related to T2 social support through $\mathrm{T} 2$ general distress, $B=.145, S E=.100, Z=$ $1.45, p=.146,95 \%$ CI $[-0.05,0.34]$.

Recall of fewer specific memories in the AMT was associated with lower social support over the next year. This was in turn associated with higher general distress at the end of the year.

\section{Discussion}

We provide the first evidence for the possible intervening role of social support in the link between reduced autobiographical memory specificity and the general distress that underlies depression and anxiety. Although the mechanisms by which reduced memory specificity might lead to general distress have been widely considered, and the social function of autobiographical memory has been explored, extant research has not considered how the specificity of recall of one's autobiographical past might influence the support one receives from significant others in daily life. Reduced autobiographical memory specificity was associated with less social support from one's social circle and romantic partner. This association in turn predicted higher general distress.

Our findings contribute to a growing literature regarding the social function of autobiographical memory (Alea \& Bluck, 2003), and in particular how the sharing of more 
specific autobiographical details may engender greater closeness between people (Alea \& Bluck, 2007; Beike et al., 2016). We extended this research by suggesting that specificity might influence perceived social support, which might in turn influence symptoms of depression and anxiety. Our findings also contribute toward research examining the relation between perceived social support and depression (e.g., Dour et al., 2014) by suggesting one pathway through which social support may come to be compromised. Our findings also contribute to literature suggesting that rAMS may be associated with a subsequent worsening of the symptoms of emotional disorders amongst healthy people (e.g., van Minnen, Wessel, Verhaak \& Smeenk, 2005). Our findings suggest a novel pathway through which rAMS may come to influence these symptoms: through its effects on the social support we receive from others.

We did not have any hypotheses regarding how the support offered in different kinds of interpersonal relationships would differentially be associated with memory specificity or general distress. However, the support offered by one's friendship group and romantic partner showed an indirect effect in our model whereas the support offered by family members was not related to our other study variables. Conceivably, support given by family members is less contingent on the style of communication about one's autobiographical past than the support given by friends. This might particularly be the case during adolescence, as in the present sample, when many friendships are still forming and consolidating, at which time greater emphasis is given to sharing and co-ruminating about one's past than at other ages (Bastin, Bijttebier, Raes, \& Vasey, 2014; Bastin, Vanhalst, Raes, \& Bijttebier, 2017). Future research should examine whether similar effects are evident in different age groups. Relatedly, although support from family members does not appear to be associated with individual differences in specificity, there is emerging evidence that thinking about these important attachment figures can influence specificity and distress (Bryant \& Bali, 2018; Selcuk, Zayas, Günaydin, Hazan \& Kross, 2012). Future research in this area could 
additionally examine the content of autobiographical memories that are retrieved and shared between people to examine the extent to which retrieval of memories of particular themes, perhaps related to early experiences and caregivers, fosters particular warmth and closeness between individuals and therefore also social support.

It is also of note that individual differences in memory specificity did not directly predict variability in general distress in the longitudinal analysis. Although there is evidence that patients differ from healthy controls with regards to the specificity of their recall in the AMT (Griffith et al., 2012; Ono et al., 2015; Sumner et al., 2014), there is growing evidence that there is little or no association between specificity and symptoms when measured continuously (Farina, Barry, Van Damme, Van Hie, \& Raes, 2018). Therefore, it may be that the relation between specificity and measures of emotional distress, particularly amongst groups of healthy participants, may only emerge when mediators such as social support are accounted for.

Although we present longitudinal findings that attest to the association between reduced specificity and less social support, we are unable to offer definitive conclusions regarding the causal relation between these variables in our current design. We hypothesised that participants who were more specific in the way that they talked about their past were more likely to attract support from other people. These effects were expected to be independent of memory valence, such that the report of positive or negative specific memories to other people was expected to endear support from them. However, we did not directly examine this process and we did not assess memory valence. Experimental research might examine this by asking unacquainted pairs of people to offer either specific or general memories of their past (Beike et al., 2016) of positive and negative valence and then measure the extent to which they subsequently support one another during stressors. It is also of note that we assumed that the way that memories are recalled in the AMT is reflective of the way that these memories are shared with others in everyday life. In the AMT used here, 
participants reported their memories verbally, rather than in written or typed form and it is conceivable that this is more reflective of normal conversation than written-forms of the AMT. To our knowledge, there are no studies that have examined this possibility and so further research in this area is warranted. In particular, research must examine the extent to which individual differences in specificity correspond with individual differences in the sharing of specific memories with other people.

There are other alternative interpretations of our findings. First, like questionnaire measures of social support, our Life Stress Interview measure of social support involves retrospective recall rather than online observation. It is conceivable that the association between reduced memory specificity and low perceived social support can be explained by poor recall of social support amongst people with reduced memory specificity. On the other hand, an impaired recall of social support would not explain the differential effects across types of interpersonal relationships, and more specifically, the lack of an association between specificity and the support given by family members. Also, although the LSI provides a measure of perceived social support through its explicit questioning of socio-emotional support and closeness within each of several relationships, the validity of the LSI relative to other more established measures of social support such as the Medical Outcomes Social Support Survey (MOS; Sherbourne \& Stewart, 1991) or the Perceived Social Support Scale (PSSS; Blumenthal et al., 1987), or even relative to naturalistic observation, has yet to be tested. Relatedly, our study only examined perceived social support and it remains unclear whether similar findings might be evident when measuring the actual support one received.

Another interpretation is that the relation between memory specificity and social support is explained by diminished interpersonal problem solving amongst people who are less specific. It may be that, compared with a person who is more specific, a person with reduced specificity is less able to use their memories to inform their selection of appropriate solutions to social problems which emerge in their life, or they may avoid these problems all 
together, and as such this might lead to impoverished social relationships (Sumner et al., 2014). This might in turn lead to elevated distress. This interpretation does not rule out the possible role of social support in the indirect association between memory specificity and general distress, but it suggests another possible mediator that might explain how reduced specificity leads to low social support.

A potential limitation of this study is that the sample had proportionally more females than males. We might expect males and females to differ in the nature of their social relationships in adolescence (Reis et al., 1993), and the interpersonal stress experienced within these relationships at this time (Rose \& Rudolph, 2006; Rudolph \& Hammen, 1999). However, we did not find any sex differences in specificity or in self-reports of social support within any of the subdomains of the LSI at either time point.

In conclusion, we present the first evidence of the indirect effect of reduced memory specificity and elevated emotional distress through poor social support. Previous research in this area has focused on the intrapersonal effects of reduced memory specificity. The analyses presented here suggests that reduced autobiographical memory specificity might have interpersonal effects that could influence emotional disorder symptoms. Future research in this area should explore this causal hypothesis by manipulating memory specificity and observing social support directly rather than relying on retrospective reports. 


\section{Acknowledgements}

This research was supported by a two-site grant from the National Institute of Mental Health to SM and REZ (R01-MH065652) and MGC (R01-MH065651). 
Declaration of interest statement

The authors have no conflicts of interest to declare. 


\section{References}

Alea, N., \& Bluck, S. (2003). Why are you telling me that? A conceptual model of the social function of autobiographical memory. Memory, 11(2), 165-178. https://doi.org/10.1080/741938207

Alea, N., \& Bluck, S. (2007). I'll keep you in mind: The intimacy function of autobiographical memory. Applied Cognitive Psychology, 21(8), 1091-1111. https://doi.org/10.1002/acp.1316

Arie, M., Apter, A., Orbach, I., Yefet, Y., \& Zalzman, G. (2008). Autobiographical memory, interpersonal problem solving, and suicidal behavior in adolescent inpatients. $\begin{array}{lll}\text { Comprehensive } & \text { Psychiatry, } & \text { 22-29(1), }\end{array}$ https://doi.org/10.1016/j.comppsych.2007.07.004

Barry, T. J., Lenaert, B., Hermans, D., Raes, F., \& Griffith, J. W. (2018). Meta-analysis of the association between autobiographical memory specificity and exposure to trauma. Journal of Traumatic Stress.

Bastin, M., Bijttebier, P., Raes, F., \& Vasey, M. W. (2014). Brooding and reflecting in an interpersonal context. Personality and Individual Differences, 63, 100-105. https://doi.org/10.1016/j.paid.2014.01.062

Bastin, M., Vanhalst, J., Raes, F., \& Bijttebier, P. (2017). Co-Brooding and Co-Reflection as Differential Predictors of Depressive Symptoms and Friendship Quality in Adolescents: Investigating the Moderating Role of Gender. Journal of Youth and Adolescence, 1-15. https://doi.org/10.1007/s10964-017-0746-9

Beike, D. R., Brandon, N. R., \& Cole, H. E. (2016). Is sharing specific autobiographical memories a distinct form of self-disclosure? Journal of Experimental Psychology: General, 145(4), 434-450. https://doi.org/10.1037/xge0000143

Blumenthal, J. A., Burg, M. M., Barefoot, J., Williams, R. B., Haney, T., \& Zimet, G. (1987). Social support, Type A behavior, and coronary artery disease. Psychosomatic Medicine, 
49(4), 331-340. https://doi.org/10.1097/00006842-198707000-00002

Bryant, R. A., \& Bali, A. (2018). Activating attachment representations impact how we retrieve autobiographical memories. Memory, 26(4), 462-467. doi:10.1080/09658211.2017.1367404

Dour, H. J., Wiley, J. F., Roy-Byrne, P., Stein, M. B., Sullivan, G., Sherbourne, C. D., ... Craske, M. G. (2014). Perceived social support mediates anxiety and depressive symptom changes following primary care intervention. Depression and Anxiety, 31(5), 436-442. https://doi.org/10.1002/da.22216

Ehlers, A., \& Clark, D. M. (2000). A cognitive model of posttraumatic stress disorder. Behavior Research and Therapy, 38, 319-345. https://doi.org/10.1016/S0005-7967(99)00123-0

Evans, J., Williams, J. M. G., O’loughlin, S., \& Howells, K. (1992). Autobiographical memory and problem-solving strategies of parasuicide patients. Psychological Medicine, 22(2), 399-405. https://doi.org/10.1017/S0033291700030348

Eysenck, H. J., \& Eysenck, S. B. G. (1975). Manual of the Eysenck Personality Questionnaire. Journal of Personality Assessment (Vol. 43). https://doi.org/10.1177/014662168000400106

Eysenck, S. B. G., Eysenck, H. J., \& Barrett, P. (1985). A revised version of the psychoticism scale. Personality and Individual Differences, 6(1), 21-29. https://doi.org/10.1016/0191$\underline{8869(85) 90026-1}$

Farina, F. R., Barry, T. J., Van Damme, I., Van Hie, T., \& Raes, F. (2018). Depression diagnoses, but not individual differences in depression symptoms, predict reduced autobiographical memory specificity. British Journal of Clinical Psychology.

Geer, J. H. (1965). The development of a scale to measure fear. Behaviour Research and Therapy, 3(1), 45-53. https://doi.org/10.1016/0005-7967(65)90040-9

Goddard, L., Dritschel, B., \& Burton, A. (1996). Role of autobiographical memory in social problem solving and depression. Journal of Abnormal Psychology, 105(4), 609-616. 
https://doi.org/10.1037/0021-843X.105.4.609

Goddard, L., Dritschel, B., \& Burton, A. (1997). Social problem solving and autobiographical memory in non-clinical depression. The British Journal of Clinical Psychology / the British Psychological Society, 36 ( Pt 3), 449-451. https://doi.org/10.1037/0021843X.105.4.609

Griffith, J. W., Kleim, B., Sumner, J. A., \& Ehlers, A. (2012). The factor structure of the Autobiographical Memory Test in recent trauma survivors. Psychological Assessment, 24(3), 640-6. https://doi.org/10.1037/a0026510

Griffith, J. W., Sumner, J. A., Debeer, E., Raes, F., Hermans, D., Mineka, S., .. Craske, M. G. (2009). An item response theory/confirmatory factor analysis of the autobiographical memory test. Memory, 17(6), 609-623. https://doi.org/10.1080/09658210902939348

Hammen, C., Ellicott, a, Gitlin, M., \& Jamison, K. R. (1989). Sociotropy/autonomy and vulnerability to specific life events in patients with unipolar depression and bipolar disorders. Journal of Abnormal Psychology, 98(2), 154-60. https://doi.org/10.1037/0021843X.98.2.154

Harris, L. S., Block, S. D., Ogle, C. M., Goodman, G. S., Augusti, E.-M., Larson, R. P., ... Urquiza, A. (2015). Coping style and memory specificity in adolescents and adults with histories of child sexual abuse. Memory, 8211(October), 1-13. https://doi.org/10.1080/09658211.2015.1068812

Hermans, D., Raes, F., \& Eelen, P. (2005). Mood and memory: A cognitive psychology perspective on maintenance of depressed mood and vulnerability for relapse. In J. Corveleyn, P. Luyten, \& S. J. Blatt (Eds.), The Theory and Treatment of Depression: Towards a Dynamic Interactionism Model (pp. 43-66). Leuven, Belgium/Mahwah, NJ: Leuven University Press/Lawrence Erlbaum Associates. https://doi.org/10.4324/9780203763995

Heron, J., Crane, C., Gunnell, D., Lewis, G., Evans, J., \& Williams, J. M. G. (2012). 40,000 
memories in young teenagers: Psychometric properties of the Autobiographical Memory Test in a UK cohort study. Memory, 20(3), 300-320. https://doi.org/10.1080/09658211.2012.656846

Ibarra-Rovillard, M. S., \& Kuiper, N. A. (2011). Social support and social negativity findings in depression: Perceived responsiveness to basic psychological needs. Clinical Psychology Review, 31(3), 342-352. https://doi.org/10.1016/j.cpr.2011.01.005

Kleim, B., \& Ehlers, A. (2008). Reduced autobiographical memory specificity predicts depression and posttraumatic stress disorder after recent trauma. Journal of Consulting \& Clinical Psychology, 76(2), 231-242. https://doi.org/10.1037/0022-006X.76.2.231

Leskelä, U., Rytsälä, H., Komulainen, E., Melartin, T., Sokero, P., Lestelä-Mielonen, P., \& Isometsä, E. T. (2006). The influence of adversity and perceived social support on the outcome of major depressive disorder in subjects with different levels of depressive $\begin{array}{llll}\text { symptoms. } & \text { Psychological } & \text { 779-788. }\end{array}$ https://doi.org/10.1017/S0033291706007276

Mattick, R., \& Clarke, C. (1998). Development and Validation of Measure of Social Phobia Scrutiny Fear and Social Interaction Anxiety. Behavior Research and Therapy, 36(455), 70. https://doi.org/10.1016/S0005-7967(97)10031-6

Naragon-Gainey, K., Prenoveau, J. M., Brown, T. A., \& Zinbarg, R. E. (2016). A comparison and integration of structural models of depression and anxiety in a clinical sample: Support for and validation of the tri-level model. Journal of Abnormal Psychology, 125(7), 853-867. https://doi.org/10.1037/abn0000197

Ono, M., Devilly, G. J., \& Shum, D. H. K. (2015). A meta-analytic review of overgeneral memory: The role of trauma history, mood, and the presence of posttraumatic stress disorder. Psychological Trauma: Theory, Research, Practice, and Policy, 8(2), 157-164. https://doi.org/http://dx.doi.org/10.1037/tra0000027

Prenoveau, J. M., Zinbarg, R. E., Craske, M. G., Mineka, S., Griffith, J. W., \& Epstein, A. M. 
(2010). Testing a hierarchical model of anxiety and depression in adolescents: A tri-level model. Journal of Anxiety Disorders, 24(3), 334-344. https://doi.org/10.1016/j.janxdis.2010.01.006

Raes, F., Hermans, D., Williams, J. M. G., Demyttenaere, K., Sabbe, B., Pieters, G., \& Eelen, P. (2005). Reduced specificity of autobiographical memory: A mediator between rumination and ineffective social problem-solving in major depression? Journal of Affective Disorders, 87(2-3), 331-335. https://doi.org/10.1016/j.jad.2005.05.004

Raes, F., Hermans, D., Williams, J. M. G., \& Eelen, P. (2007). A sentence completion procedure as an alternative to the autobiographical memory test for assessing overgeneral memory in non-clinical populations. Memory, 15(5), 495-507. https://doi.org/10.1080/09658210701390982

Raes, F., Williams, J. M. G., \& Hermans, D. (2008). Preliminary evaluation of a training program to increase autobiographical memory specificity in patients with depressive complaints. In 6th Special Interest Meeting on Autobiographical Memory and Psychopathology. Amsterdam, Netherlands.

Reis, H. T., Lin, Y.-C., Bennett, M. E., \& Nezlek, J. B. (1993). Change and consistency in social participation during early adulthood. Developmental Psychology, 29(4), 633-645. https://doi.org/10.1037/0012-1649.29.4.633

Rose, A. J., \& Rudolph, K. D. (2006). A review of sex differences in peer relationship processes: Potential trade-offs for the emotional and behavioral development of girls and boys. Psychological Bulletin, 132(1), 98-131. https://doi.org/10.1037/00332909.132.1.98

Rudolph, K. D., \& Hammen, C. (1999). Age and Gender as Determinants of Stress Exposure, Generation, and Reactions in Youngsters: A Transactional Perspective. Child Development, 70(3), 660-677.

Selcuk, E., Zayas, V., Günaydin, G., Hazan, C., \& Kross, E. (2012). Mental representations of 
attachment figures facilitate recovery following upsetting autobiographical memory recall. Journal of Personality and Social Psychology, 103(2), 362-378. doi:10.1037/a0028125

Sherbourne, C. D., \& Stewart, A. L. (1991). The MOS social support survey. Social Science and Medicine, 32(6), 705-714. https://doi.org/10.1016/0277-9536(91)90150-B

Stewart, T. M., Hunter, S. C., \& Rhodes, S. M. (2017). A narrative synthesis of the applicability of the CaR-FA-X model in child and adolescent populations: a systematic review. Memory, 25(9), 1161-1190. https://doi.org/10.1080/09658211.2016.1275699

Stice, E., Ragan, J., \& Randall, P. (2004). Prospective Relations between Social Support and Depression: Differential Direction of Effects for Parent and Peer Support? Journal of Abnormal Psychology, 113(1), 155-159. https://doi.org/10.1037/0021-843X.113.1.155

Sumner, J. A., Griffith, J. W., \& Mineka, S. (2010). Overgeneral autobiographical memory as a predictor of the course of depression: A meta-analysis. Behaviour Research and Therapy, 48(7), 614-625. https://doi.org/10.1016/j.brat.2010.03.013

Sumner, J. A., Mineka, S., Adam, E. K., Craske, M. G., Vrshek-schallhorn, S., WolitzkyTaylor, K., \& Zinbarg, R. E. (2014). Testing the CaR - FA - X Model : Investigating the Mechanisms Underlying Reduced Autobiographical Memory Specificity in Individuals With and Without a History of Depression, 123(3), 471-486.

Sutherland, K., \& Bryant, R. A. (2008). Social problem solving and autobiographical memory in posttraumatic stress disorder. Behaviour Research and Therapy, 46(1), 154-161. https://doi.org/10.1016/j.brat.2007.10.005

Takano, K., Mori, M., Nishiguchi, Y., Moriya, J., \& Raes, F. (2017). Psychometric properties of the written version of the autobiographical memory test in a japanese community sample. Psychiatry Research, 248(December 2016), 56-63. https://doi.org/10.1016/j.psychres.2016.12.019

van Minnen, A., Wessel, I., Verhaak, C., \& Smeenk, J. (2005). The relationship between 
autobiographical memory specificity and depressed mood following a stressful life event: a prospective study. The British Journal of Clinical Psychology, 44(3), 405-415. doi:10.1348/014466505X29648

Van Vreeswijk, M. F., \& De Wilde, E. J. (2004). Autobiographical memory specificity, psychopathology, depressed mood and the use of the Autobiographical Memory Test: A meta-analysis. Behaviour Research and Therapy, 42(6), 731-743. https://doi.org/10.1016/S0005-7967(03)00194-3

Vanderveren, E., Bijttebier, P., \& Hermans, D. (2017). The Importance of Memory Specificity and Memory Coherence for the Self: Linking Two Characteristics of Autobiographical Memory. Frontiers in Psychology, 8(December), 1-13. https://doi.org/10.3389/fpsyg.2017.02250

Watson, D., Weber, K., Assenheimer, J. S., Clark, L. A., Strauss, M. E., \& McCormick, R. A. (1995). Testing a tripartite model: I. Evaluating the convergent and discriminant validity of anxiety and depression symptom scales. Journal of Abnormal Psychology, 104(1), 314. https://doi.org/10.1037/0021-843X.104.1.3

Williams, J. M. G. (2006). Capture and rumination, functional avoidance, and executive control (CaRFAX): Three processes that underlie overgeneral memory. Cognition and Emotion. https://doi.org/10.1080/02699930500450465

Williams, J. M. G., Barnhofer, T., Crane, C., Herman, D., Raes, F., Watkins, E., \& Dalgleish, T. (2007). Autobiographical memory specificity and emotional disorder. Psychological Bulletin, 133(1), 122-148. https://doi.org/10.1037/0033-2909.133.1.122

Williams, J. M. G., \& Broadbent, K. (1986). Autobiographical memory in suicide attempters. Journal of Abnormal Psychology, 95(2), 144-149. https://doi.org/10.1037/0021843X.95.2.144

Zimmerman, M., Coryell, W., Corenthal, C., \& Wilson, S. (1986). A Self-Report Scale to Diagnose Major Depressive Disorder. Archives of General Psychiatry, 43(11), 1076- 
1081. https://doi.org/10.1001/archpsyc.1986.01800110062008

Zinbarg, R. E., Mineka, S., Craske, M. G., Griffith, J. W., Sutton, J., Rose, R. D., ... Waters, A. M. (2010). The Northwestern-UCLA youth emotion project: Associations of cognitive vulnerabilities, neuroticism and gender with past diagnoses of emotional disorders in adolescents. Behaviour Research and Therapy, 48(5), 347-358. https://doi.org/10.1016/j.brat.2009.12.008 
Table 1. Linear regression

\begin{tabular}{|c|c|c|c|}
\hline Dependent variable: T1 Prop. Spec. & $b$ & $\mathrm{SE}(b)$ & $\beta$ \\
\hline Closest friend & .010 & .020 & .046 \\
\hline Social circle & .056 & .025 & $.220 *$ \\
\hline Romantic partner & .054 & .026 & $.181^{*}$ \\
\hline Family & -.003 & .020 & -.012 \\
\hline
\end{tabular}

Note. Linear regression for Time 2 measures of social support and their relation with the proportion of specific memories recalled in the Autobiographical Memory Test (AMT; Prop. Spec.) measured at Time $1 .{ }^{*} p<.05$. 
Table 2. Correlation matrix

\begin{tabular}{lllllll}
\hline & & 1. & 2. & 3. & 4. & 5. \\
\hline 1. T1 Prop. Spec. & - & & & & \\
2. T1 Support & $.26 * *$ & - & & & \\
3. T2 Support & $.34 * * *$ & $.44 * * *$ & - & & \\
4. T1 Distress & .13 & $-.29 * * *$ & $-.17 *$ & - & \\
5. T2 Distress & -.04 & $-.22 * *$ & $-.30^{* * *}$ & $.57 * * *$ & -
\end{tabular}

Note. Pearson's correlation coefficients for each study variable where T1 and T2 refer to the assessment times. Prop. Spec refers to the proportion of specific memories recalled in Autobiographical Memory Test (AMT). Support refers to self-reports of the social support given by close friends and romantic partners. Distress refers to factors scores for the general distress construct. $p<.05^{*} ; p<.01 * * ; p<.001 * * *$. 
Figure 1. Path diagram

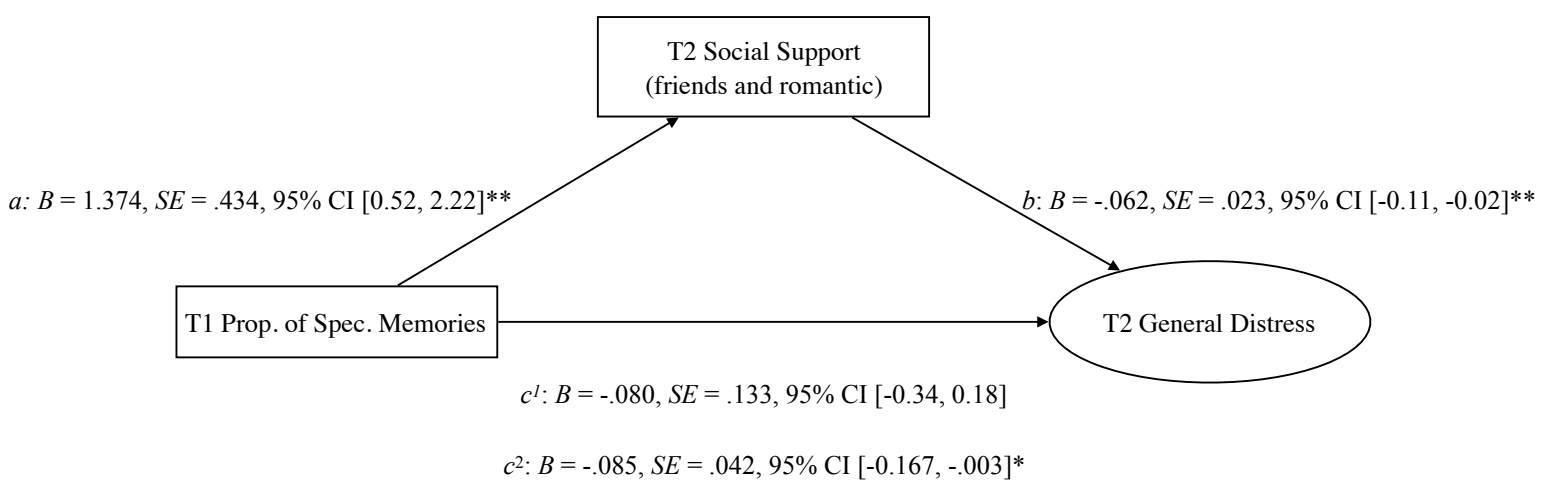

Note. Longitudinal model of the intervening role of self-reported social support from one's friends and romantic partners in the relation between the proportion of specific memories recalled in the Autobiographical Memory Test (AMT) and a General Distress factor made up of the symptoms of anxiety and depression. Pathway $c^{2}$ represents the indirect pathway. Pathway $a$ takes into account the variance in T2 social support explained by T1 social support. Pathway $c^{2}$ takes into account both T1 social support and T1 general distress. ${ }^{*} p<.05,{ }^{* *} p<$ .01 . 